\title{
Espaço domiciliar de casos de hanseníase, compartilhamento de genes e ambiente social: estudo de 61 famílias
}

Introdução: A hanseníase é doença infecciosa crônica causada pelo Micobacterium leprae e acomete principalmente a pele e nevos periféricos. O Brasil é responsável por $93 \%$ dos casos notificados no continente americano. A ausência de ferramentas mais poderosas, como vacina específica, faz com que o controle da doença dependa do diagnóstico precoce e tratamento oportuno. Assim, o exame de contatos domiciliares torna-se imprescindível já que a fonte de infecção é o indivíduo bacilífero sem tratamento.

Palavras-chave: ambiente; família; hanseníase; transmissão

Objetivos: Estudar a cadeia de transmissão da hanseníase no meio familiar, em área endêmica.

\section{Metodologia: Estudo transversal}

Resultados: Avós, irmãos, tios e pais foram identificados como casos índices (multibacilares e primeiros a adoecer) de hanseníase na família. Foram identificados como principais casos índices pais, filhos e irmãos. No total de 61 famílias estudadas, os pais (pai ou mãe) foram casos primários em 16 delas (26,2\%). Nessas 16 famílias, 31 casos secundários foram gerados, sendo 28 casos em filhos. Observou- se que também os filhos foram casos índices, tendo inclusive contaminado um dos pais, em cinco famílias. A proporção de pai afetado para mãe afetada, quando o caso índice era o filho, foi de 3:1 (3 pais e 1 mãe), diferença também observada quando os filhos foram afetados, quando um dos genitores era o caso índice, na proporção de 16 homens para 12 mulheres. Irmãos também foram relevantes na disseminação da doença no núcleo familiar, e mais uma vez houve predominância dos irmãos masculinos afetados sobre os femininos (8 homens e 4 mulheres), enquanto casos entre cônjuges ocorreram em apenas duas famílias. A figura abaixo mostra a importância da consangüinidade com 28 filhos afetados nessas 16 famílias. 
Figura 1 Casos familiares de hanseníase

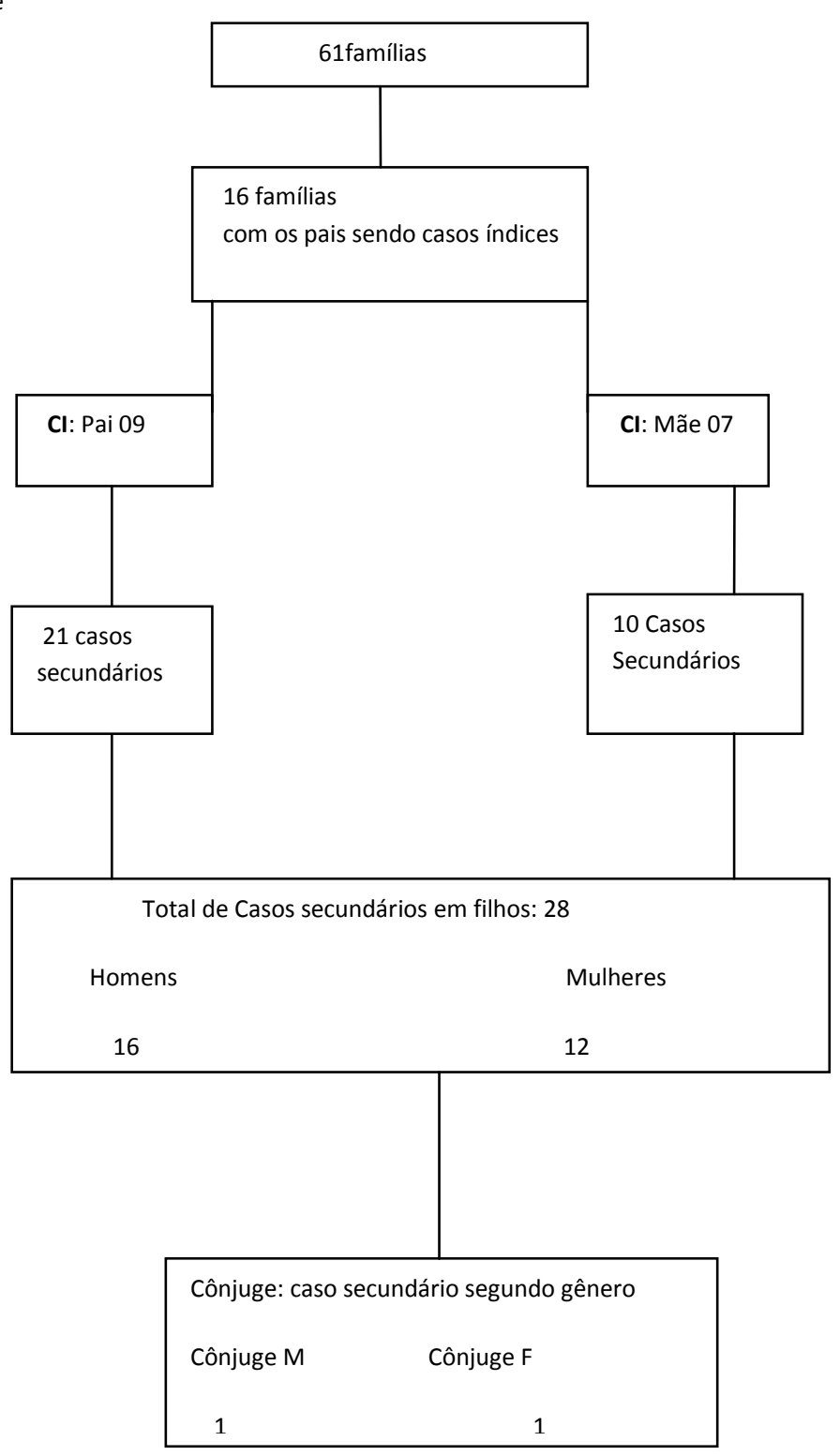

Discussão

Mesmo considerando que em áreas de alta endemicidade a transmissão da hanseníase possa ocorrer em ambiente de trabalho ou outras situações de contato próximo e repetido, dados de literatura apontam os contatos domiciliares até dez vezes mais suscetíveis à infecção que do a população geral. Apesar disto, o índice de exames de contatos no Brasil é bem abaixo do esperado. Em nosso estado apenas $46,4 \%$ dos contatos registrados foram examinados em 2010, sendo um estado hiperendêmico com taxa de deteç̧ão geral de 44,83/100.000 e detecção em menores de 15 anos de 11,28/100.000. Este estudo enfatiza a importância do 
espaço domiciliar na vigilância epidemiológica visando interromper a cadeia de transmissão da hanseníase . Ressalta a relevância de estudos genéticos que estão permitindo conhecer alguns polimorfismos associados à susceptibilidade e resistência a hanseníase e propõe o foco na consciência de risco da família, quanto ao surgimento de casos secundários intradomiciliares, especialmente sendo um dos genitores bacilífero, como demonstra a figura 2 .

figura 2: foco de transmissão familiar: mãe que contamina um segundo filho ( a criança do meio nesta foto) e dois irmãos.

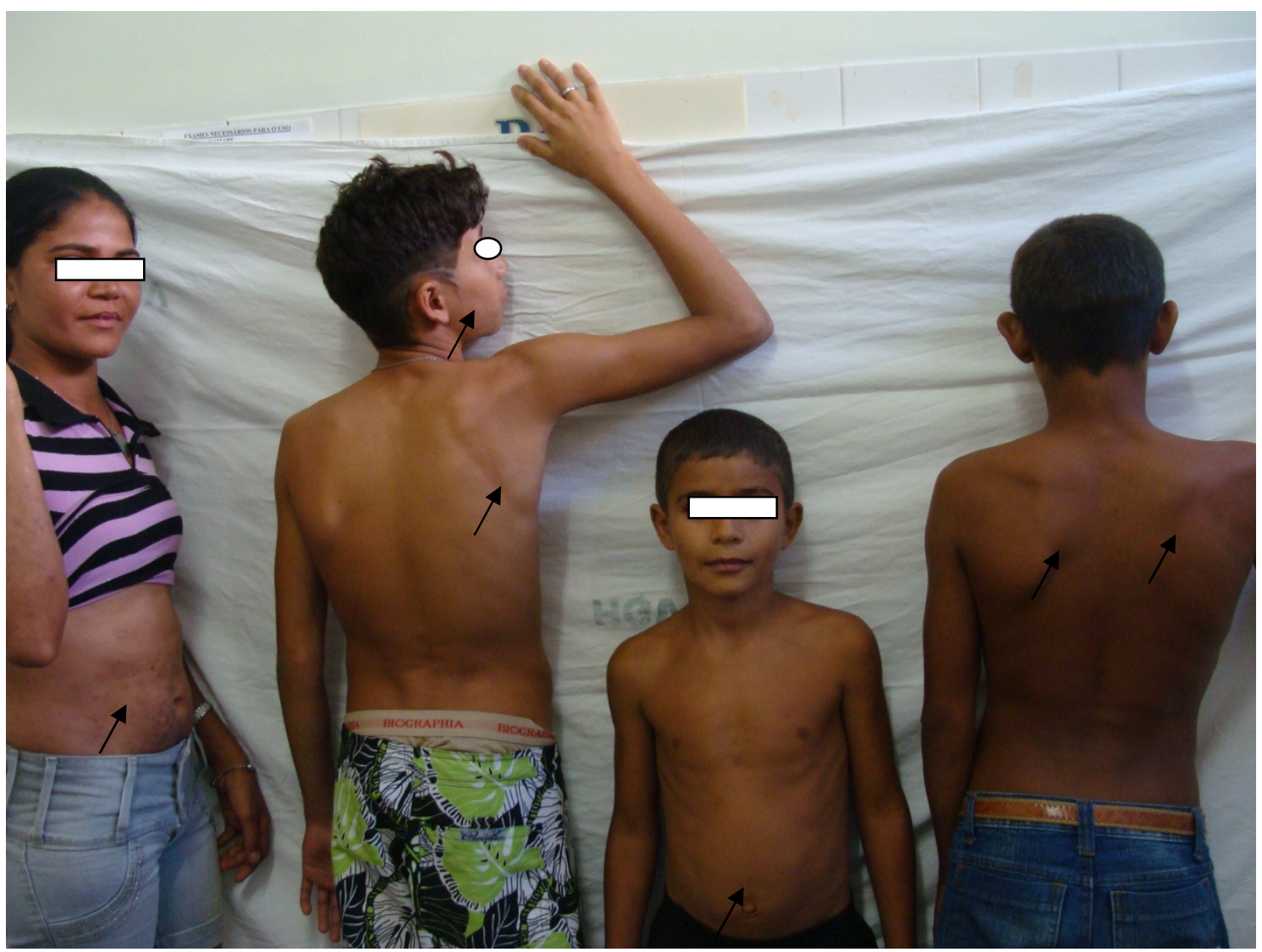

Figura 2

1. Mãe (já em tratamento): nódulos disseminados em abdome e membros superiores

2.Manchas pouco
infiltradas em
dorso, face e
membro sun

2.Manchas pouco dorso, face membro sun
3. Lesões eritematosas em tronco,

com leve
4. Lesões

eritematosas em dorso, com leve infiltração

Conclusão: O núcleo familiar deve ser o foco de atenção no controle da hanseníase. Neste estudo, o sexo masculino teve papel preponderante na disseminação da doença, com mais pais afetados, talvez pelo diagnóstico tardio. $O$ dobro de filhos homens afetados, no entanto, aponta para a possibilidade do homem ser mais susceptível a hanseníase "per se". São necessários mais estudos de gênero na cadeia de transmissão da doença. 


\section{Referências Bibliográficas}

1. Ministério da Saúde. Secretaria de Vigilância a Saúde, PNCH: Boletim Epidemiológico, 2008.

2. Secretaria de Saúde do Estado do Piauí -SESAPI; Programa de Controle da Hanseníase: dados parciais de 2010.

3. Miranzi, SSC; Pereira, LHM; Nunes AA. Perfil Epidemiológico da Hanseníase em um município brasileiro, no período de 2000 a 2006. Ver da Sociedade Brasileira de Medicina Tropical 43 (1):62-67, jan-fev,2010

4. Costa ALF, Oliveira ML Wan Del Rei. Falhas da vigilância epidemiológica da hanseníase: 4 casos multibacilares em crianças, no estado do PI. Hansen Int 2009; 34(2): 41-46.

5. Santos, AS; Castro, DS; Falqueto, A. Fatores de risco para transmissão da hanseníase. Ver Bras. Enferm. Brasília, 2008; 61/(esp):738-43

6. Bochud, P. Y., T. R. Hawn, et al. Toll-like receptor 2 (TLR2) polymorphisms are associated with reversal reaction in leprosy. J Infect Dis, v.197, n.2, Jan 15, p.253-61. 2008.

7. Gomes CCD, Pontes MAA, Gonçalves HS, Penna GO. Perfil clínico-epidemiológico dos pacientes diagnosticados com hanseníase em um centro de referência na região nordeste do Brasil. Anais Bras Dermatol 2005; 8 (supl 3): 283-288.

8. Mira, M. T., A. Alcais, et al. Susceptibility to leprosy is associated with PARK2 and PACRG. Nature, v.427, n.6975, Feb 12, p.636-40. 2004.

9. Vijayakumaran, P., K. Jesudasan, et al. Does MDT arrest transmission of leprosy to household contacts? Int J Lepr Other Mycobact Dis, v.66, n.2, Jun, p.125-30. 1998. 